\title{
Circadian regulation of metabolic homeostasis: causes and consequences
}

This article was published in the following Dove Press journal:

Nature and Science of Sleep

27 May 2016

Number of times this article has been viewed

\section{Graham R McGinnis Martin E Young}

Division of Cardiovascular Disease, Department of Medicine, University of Alabama at Birmingham, Birmingham, AL, USA
Correspondence: Martin E Young Division of Cardiovascular Disease, Department of Medicine, University of Alabama at Birmingham, 703 19th Street South, ZRB 308, Birmingham, AL 35294, USA

Tel +l 2059342328

Fax +l 2059755104

Email meyoung@uabmc.edu
Abstract: Robust circadian rhythms in metabolic processes have been described in both humans and animal models, at the whole body, individual organ, and even cellular level. Classically, these time-of-day-dependent rhythms have been considered secondary to fluctuations in energy/nutrient supply/demand associated with feeding/fasting and wake/sleep cycles. Renewed interest in this field has been fueled by studies revealing that these rhythms are driven, at least in part, by intrinsic mechanisms and that disruption of metabolic synchrony invariably increases the risk of cardiometabolic disease. The objectives of this paper are to provide a comprehensive review regarding rhythms in glucose, lipid, and protein/amino acid metabolism, the relative influence of extrinsic (eg, neurohumoral factors) versus intrinsic (eg, cell autonomous circadian clocks) mediators, the physiologic roles of these rhythms in terms of daily fluctuations in nutrient availability and activity status, as well as the pathologic consequences of dyssynchrony.

Keywords: circadian rhythm, circadian clocks, metabolic homeostasis, neurohumoral factors, dyssynchrony, time-of-day-dependent rhythms

\section{Introduction}

Metabolism can be broadly defined as the chemical processes that occur within a living organism to maintain life. Substrate/energy metabolism refers to the process of conversion or transfer of carbon/energy from one molecule to another. This is achieved through highly dynamic and strictly regulated metabolic pathways composed of a series of enzyme-catalyzed reactions, facilitating conversion of an initial substrate to a final end product. It is essential that these processes retain sufficient flexibility, thereby maintaining nutrient and energy balance within a physiologic range (ie, metabolic homeostasis). By definition, metabolism is in constant flux, requiring consideration of the fourth dimension (ie, time). This consideration highlights the need for consideration of temporal orchestration of metabolism at the whole body, tissue, and substrate-specific levels. Circadian (derived from the Latin terms circaand -diem, meaning "around the day") rhythms refer to processes that occur in an approximately 24-hour timescale. The purpose of this paper is, therefore, to provide a comprehensive overview of circadian rhythms in metabolic homeostasis, including the relative contributions of extrinsic (eg, insulin) and intrinsic (eg, circadian clocks) factors governing these rhythms, and highlight the pathologic consequences following their disruption. 


\section{Rhythms in metabolism}

Given the focus of this paper, it is important to define "circadian rhythms in metabolism". Technically, to be considered "circadian", processes must 1) oscillate with a periodicity of 24 hours under constant conditions (ie, in the absence of external cues); 2) be entrainable to external cues; and 3) persist across a range of physiological temperatures. ${ }^{1}$ In reality, the majority of studies investigate diurnal or time-of-day-dependent, as opposed to circadian, rhythms because of the presence of external cues (eg, light/ dark cycle). Nomenclature has developed to refer to these paradigms separately, where zeitgeber time (ZT) defines the time during light/dark cycles (ZT0 being the beginning of the light phase) and circadian time defines the time during constant conditions (eg, constant darkness). Accordingly, here we consider both circadian and diurnal rhythms. Metabolic flux through a pathway can be assessed in vivo, ex vivo, and in vitro through a number of methodologies including, but not limited to, following the rate of substrate utilization (eg, oxygen consumption in isolated mitochondria, cells, permeabolized tissues, or in vivo respirometry) or product generation (eg, accumulation of labeled products in cells/tissues). In the latter case, both stable isotopes and radiolabeled tracers have been utilized successfully in intact tissues and cells. Collectively, these parameters are considered primary measures of metabolism (Figure 1). Metabolite analysis, both unbiased (metabolomics), and/ or candidate assessments offer supplemental information. However, since these assessments are at "steady-state" levels, they may not directly indicate the flux of carbon through a pathway, and are thus considered secondary measures. This point is exemplified by intramyocellular adenosine triphosphate (ATP) levels; during exercise, ATP levels decrease slightly in cardiac muscle (ie, steady-state metabolite), yet rates of ATP synthesis (ie, flux) increase dramatically to meet energetic demands. ${ }^{2}$ Similar to metabolite measures, the assessment of the activity of an enzyme in an in vitro assay is considered a secondary measure of metabolism (as enzymatic activity in situ is dependent on substrate and allosteric effector levels, subcellular localization, and protein-protein interactions, which are not recapitulated in in vitro assays). In contrast, protein and gene expression (as well as posttranslational modifications) are far removed from metabolic fluxes and can be considered tertiary measures, which have the potential to provide mechanistic insight with regards to causes (and in some cases, consequences) of perturbations in metabolic fluxes. The following subsections will focus initially on rhythms in macronutrient (ie, carbohydrate, lipid, and protein) utilization in numerous tissues involved in metabolic homeostasis (eg, intestine, liver, adipose, and skeletal muscle). Figure 2 summarizes the information explained in this section, and highlights time-of-day-dependent metabolic rhythms in ad libitum fed rodents. In all cases, hypotheses will be

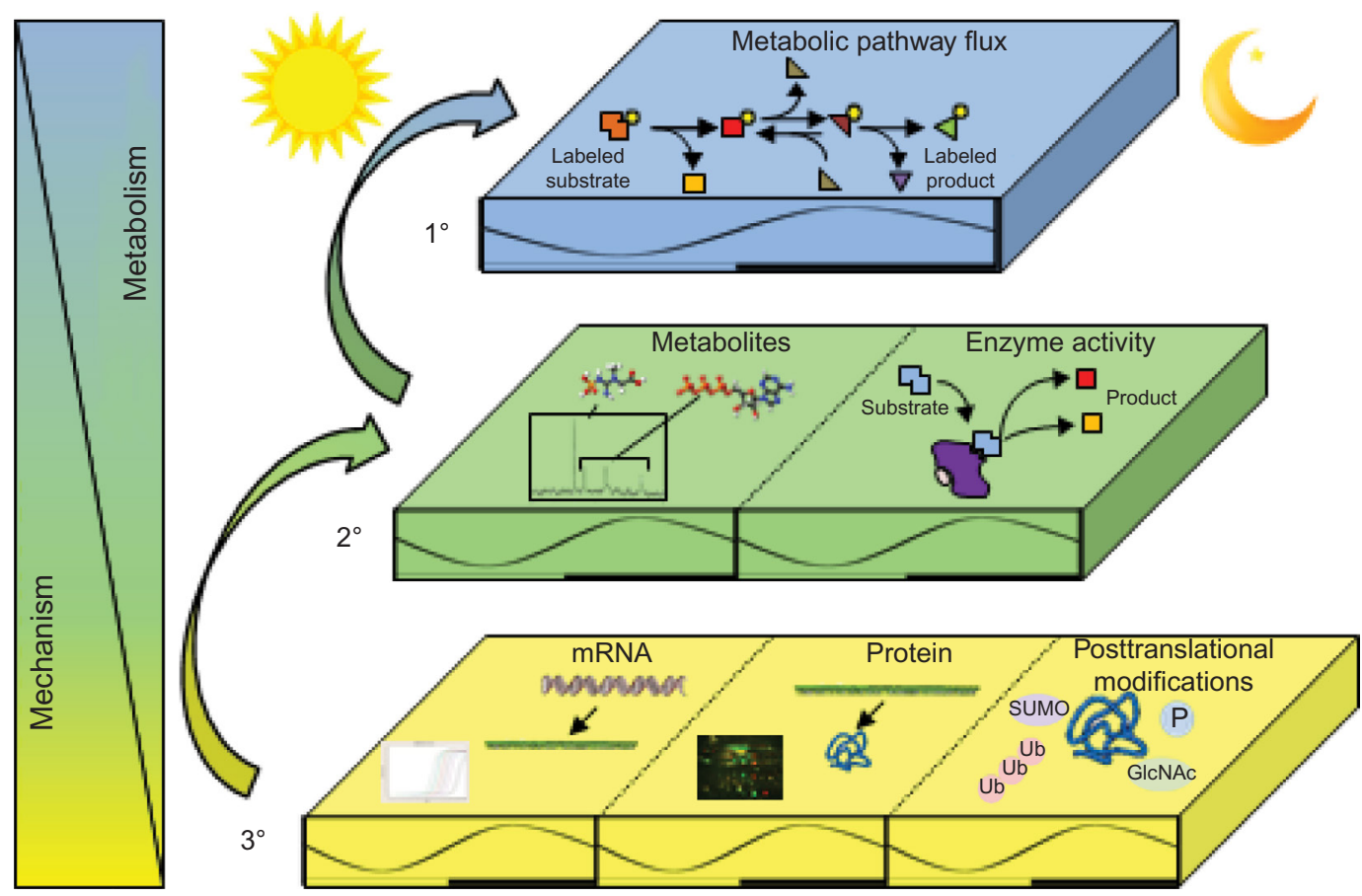

Figure I Measures and mediators of metabolic flux.

Abbreviations: SUMO, sumoylation; Ub, ubiquitination; GlcNAc, O-linked N-acetylglucosamine; P, phosphorylation. 


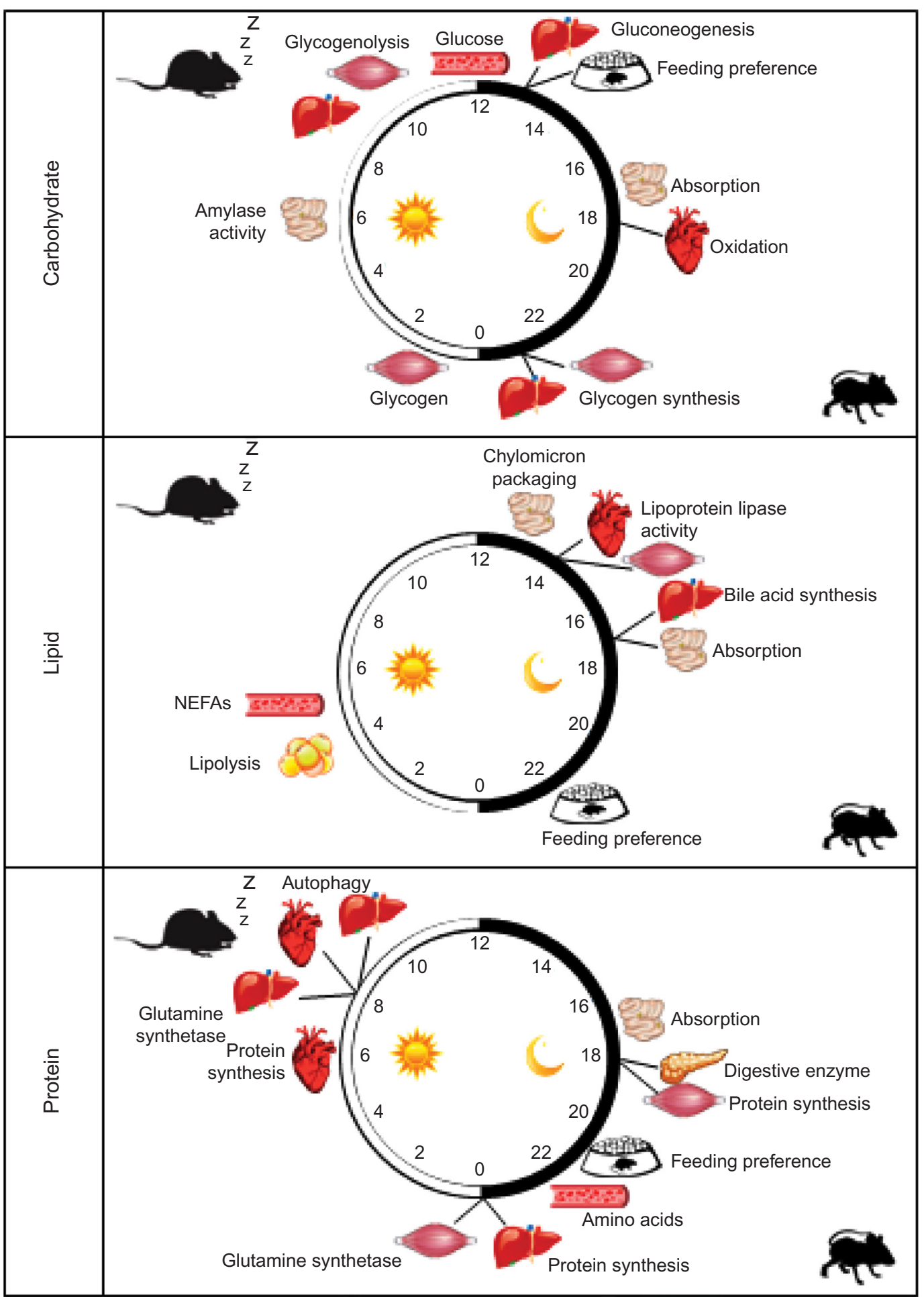

Figure 2 Time-of-day-dependent rhythms in glucose, lipid, and protein/amino acid metabolism in rodent models. Abbreviation: NEFAs, nonesterified fatty acids.

provided regarding the potential physiologic advantage of temporal synchronization of these processes.

\section{Carbohydrate}

Carbohydrates are complex biomolecules (mono-, di-, and polysaccharides) representing the most abundant carbon source on Earth; for the sake of simplicity, we will focus on glucose metabolism. As with other nutrients, glucose homeostasis is the product of dietary intake and digestion/ absorption, endogenous production, and tissue utilization. To maintain blood glucose levels within a physiological range, these processes must work in concert, an undertaking 
involving the interplay of multiple organ systems. Diurnal patterns of feeding and concomitant rhythms in blood glucose levels have been observed in humans and animal models. Carbohydrate preference is increased early in the feeding period (with a later shift toward proteins and fats).$^{3-5}$ Following ingestion, polysaccharides (eg, starch) are hydrolyzed to di- and monosaccharides by $\alpha$-amylase. Parotid and pancreatic $\alpha$-amylase activities exhibit a rhythm in both fed and fasted rats, peaking during the middle of the light phase, ${ }^{6-8}$ likely in anticipation of food intake. The rate of glucose absorption in the small intestine also fluctuates throughout the day ${ }^{9}$ glucose uptake in the intestine (duodenum, jejunum, and ileum) is increased during the middle of the active period, both in vivo (in situ intestinal loop) and ex vivo (isolated tissues). ${ }^{10-13}$ These findings are consistent with increased gene and protein expression of intestinal sodium-glucose cotransporter 1 and GLUT5, as well as GLUT2 (which is responsible for exporting monosaccharides from intestinal epithelial cells into the bloodstream) at the beginning of the active period. ${ }^{13-15}$ Collectively, these findings illustrate temporal synchrony between anticipation of food intake ( $\alpha$-amylase), carbohydrate preference, and glucose absorption.

Circulating glucose levels are a function of reciprocal rates of glucose import into, and export from, the blood. Interestingly, following a bolus infusion of glucose, circulating glucose levels increase to different extents depending on the time of day, ${ }^{16}$ with the lowest increment at the beginning of the active period in both rodents and humans, ${ }^{17}$ reflecting timeof-day-dependent differences in rates of glucose disposal by tissues, such as liver, skeletal muscle, and adipose. ${ }^{18-20}$ Upon uptake into target tissues, glucose has multiple oxidative and nonoxidative fates. This includes storage as glycogen. In both the liver and skeletal muscle, glycogen synthesis peaks at the end of the active period (whereas glycogen breakdown peaks at the end of the sleep period). ${ }^{21-25}$ In isolated skeletal muscle, rhythms in insulin-mediated glucose disposal have been reported; glycogen synthesis exhibits a biphasic pattern in rat soleus muscle, peaking at both the onset of the active and sleep phases. ${ }^{26}$ During periods of fasting, hepatic glucose output increases to help maintain homeostasis, in part, due to increased gluconeogenesis. Importantly, tracer studies have revealed that gluconeogenic flux peaks at the end of the sleep (fasting) period, which is associated with greater hepatic phosphoenolpyruvate carboxykinase expression. ${ }^{27}$

Collectively, rhythms in carbohydrate metabolism are apparent at multiple levels, likely optimizing performance and homeostasis during daily fluctuations in energetic demands (eg, increase blood glucose at the beginning of active period in anticipation of foraging for food, avoiding predation, etc) and feeding status (eg, increased production of $\alpha$-amylase and insulin at the beginning of the active period to maximize efficient carbohydrate digestion and glucose uptake).

\section{Lipid}

As with other nutrients, protein and amino acid homeostasis is achieved through a balance between ingestion/digestion/ absorption, de novo synthesis, and utilization. Evidence for stringent protein homeostasis includes observations that mice given foods of differing protein content modify their food intake to consume the same total protein amount. ${ }^{3}$ In terms of rhythms, preference for protein-enriched foods increases later in the active period. ${ }^{4}$ Following ingestion, proteins are hydrolyzed by digestive enzymes and broken down into diand tripeptides, as well as amino acids. Pepsinogen, a major digestive enzyme, is secreted in a time-of-day-dependent manner, peaking in the middle of the rest period. Conversely, pepsinogen activation peaks during the active period due to increased acid secretion at this time. ${ }^{28}$ Similarly, chymotrypsin secretion peaks during the active period in rats. Interestingly, rhythms in the profile of pancreatic secretions persisted, albeit severely attenuated, during 48 hours fasting ${ }^{29}$ suggesting anticipation, as opposed to response, of food consumption. Meal feeding-induced pancreatic secretions also exhibit a time-of-day dependence in pigs, with greater responses during the active period..$^{30}$ Peptide and amino acid absorption in the small intestine occurs in a diurnal fashion, peaking during the active phase, in association with increased gene ${ }^{13}$ and protein $^{31}$ expression (peak at ZT12, both) of peptide transporter 1 . Rhythms in circulating levels of amino acids (asparagine and tryptophan) are present in humans and rodents, with increased levels in the late active period compared to waking. ${ }^{32-35}$ When healthy human subjects consumed a high protein load in the morning ( $8 \mathrm{am}$ ), a greater acute increase of amino acids in the circulation was observed, compared to the same protein load in the evening $(8 \mathrm{pm}) .{ }^{32}$ However, the peak in circulating amino acid levels is independent of total dietary protein intake and is unchanged by either high or low protein diets. ${ }^{32}$

Circulating amino acids are not only derived from protein digestion and absorption; multiple tissues generate and release distinct amino acids in a quantitatively appreciable manner. Two examples include alanine and glutamine. In the latter case, skeletal muscle is considered a major site of glutamine synthesis and release, which appears to occur in 
a time-of-day-dependent manner. ${ }^{36-38}$ Proteolysis is also a significant means of mobilizing "stored" amino acids. Two major mechanisms involved in protein and organelle turnover include the proteasome and autophagy. ${ }^{39,40}$ Remarkably, little information is available regarding time-of-day-dependent rhythms in proteasome-mediated protein breakdown. Indirect evidence stems from microarray studies, having identified a number of ubiquitin ligases and proteasome components as fluctuating at a gene expression level in a time-of-daydependent manner. ${ }^{41}$ Accumulating evidence suggests that autophagic degradation of subcellular constituents occurs in a diurnal fashion. Electron micrographs initially revealed that autophagic vacuole accumulation varies over the course of the day, suggesting greatest autophagy during the sleep phase in the rat liver (and heart). ${ }^{42,43}$ Furthermore, injecting mice with a lysosomal protease inhibitor leupeptin (which inhibits terminal stages of autophagosome breakdown) exposed increased autophagic flux in the liver during the sleep phase. ${ }^{44}$

Circulating amino acids are taken up and utilized by cells for a number of purposes, including catabolism, conversion to other nitrogen-containing compounds (eg, carnitine, creatine, neurotransmitters, etc), and incorporation into protein. The latter process appears to be time-of-day dependent. Protein synthesis in skeletal muscle peaks during the dark phase, corresponding to a period of increased food intake, increased circulating amino acids, and increased insulin in nocturnal rodents. ${ }^{45}$ In contrast, protein synthesis appears to peak at the end of the active period in the liver, and in the middle of the sleep phase for the heart. ${ }^{46,47}$ Collectively, these observations suggest that time-of-day-dependent rhythms in amino acid metabolism differ in distinct tissues, which is likely important for whole-body homeostasis. However, several questions remain unanswered, including details regarding the importance of circadian rhythms in protein turnover and the relative contributions of amino acid utilization versus de novo synthesis in circulating level rhythms.

\section{Lipid}

Lipids are more than just a metabolic fuel source, serving also as membrane constituents and modulators of transcription/ translation, signaling transduction, and cell death. Accordingly, perturbations in lipid homeostasis can lead to a host of pathologies, including diabetes mellitus and cardiovascular disease. Rhythms in processes affecting lipid homeostasis have been reported at multiple levels. For example, macronutrient preference studies indicate a greater desire for fatenriched foods later in the active period. ${ }^{3}$ Upon ingestion, lipids are emulsified by bile salts and enzymatically digested by lipases into fatty acids and monoacylglycerides. Diurnal rhythms in bile acid synthesis were identified decades ago in rats, peaking during the dark period, ${ }^{48}$ immediately following peak expression of cholesterol $7 \alpha$-hydroxylase - the rate-limiting enzyme in bile acid synthesis. ${ }^{49-52}$ Rhythms in total bile acid synthesis in rats in vivo persist during fasting, suggesting anticipation of food intake. ${ }^{48}$ These rhythms were similar for individual bile acids (cholate, chenodeoxycholate, $\alpha / \beta$-muricholate) investigated, which all reached a maximum during the active phase. ${ }^{48}$ Likewise, rhythms in lipoprotein lipase (LPL) activity in the heart and skeletal muscle are highest during the active period. ${ }^{53}$ Following digestion, fatty acids and monoacylglycerides are absorbed into the intestinal enterocytes for further processing and packaging. Using in situ loops of small intestine, greater rates of cholesterol and lipid absorption have been reported during the active phase. ${ }^{13}$ Dietary lipids are then packaged into chylomicrons within enterocytes, before being secreted into the lymphatics. Packaging/secretion of chylomicrons is regulated in part by the intestinal microsomal triglyceride transfer protein (MTP); MTP mRNA, protein, and activity increase during the active phase in enterocytes. ${ }^{13,54}$

Diurnal rhythms in circulating lipid species have been reported in humans and animal models. ${ }^{55-60}$ Liquid chromatography/gas chromatography-mass spectroscopy analysis of blood samples taken from males under "constant conditions" (40 hours constant dim light, hourly nutrition, enforced posture with no sleep) revealed peak circulating lipids between morning and noon. ${ }^{55}$ Interestingly, in a lipidomic study in healthy humans, a significant variation of peaks of different lipid species measured between individuals was found, suggesting the existence of metabolomic chronotypes. ${ }^{56}$ In order for esterified fatty acids within circulating triglyceride to enter a tissue, it must be released, a reaction catalyzed by LPL; LPL activity exhibits a diurnal pattern in various tissues, peaking during the active phase in adipose. ${ }^{61}$ De novo fatty acid synthesis requires enzymes such as acetyl-CoA carboxylase, fatty acid synthase, and fatty acid-binding protein, which are all more abundant during the active phase. ${ }^{62}$ Synthesis of triglycerides in the liver occurs in a rhythmic fashion, increasing during the feeding period. ${ }^{63,64}$ Conversely, breakdown of triglycerides and mobilization of free fatty acids from adipose tissue also fluctuate rhythmically, which are increased during the light phase in ad libitum fed rats. ${ }^{65}$

\section{Extrinsic mediators}

Circadian rhythms in metabolism could be driven by various extrinsic or intrinsic mediators. A collection of extrinsic 
factors known to regulate metabolic processes oscillate in a time-of-day-dependent manner, often being considered a reflection of environmental and/or behavioral rhythms. Diurnal rhythms in neuroendocrine factors, and/or target tissue sensitivity, undoubtedly serve to optimize diverse metabolic demands throughout daily cycles of feeding and fasting, as well as rest and activity. Here, four key metabolically relevant neurohumoral factors (ie, insulin, cortisol, growth hormone, epinephrine/norepinephrine) will be discussed, although others likely play important roles (eg, melatonin, ghrelin, adiponectin, leptin, testosterone).

\section{Insulin}

Insulin, produced/secreted by pancreatic $\beta$-cells, plays an important role in nutrient sensing. ${ }^{66}$ During the postprandial state, increased insulin secretion stimulates nutrient uptake, utilization, and storage in metabolically active tissues, including the liver, adipose tissue, and muscle. ${ }^{66}$ For example, insulin: 1) increases glucose uptake via translocation of GLUT4 to the membrane in muscle and adipose; 2) attenuates hepatic gluconeogenesis; 3) stimulates glyconeogenesis in liver and muscle; and 4) activates protein synthesis in numerous tissues. Circulating insulin levels fluctuate in a time-of-day-dependent manner (peaking late in the active period). Increased food intake during the active period does not appear to be the sole determinant of these rhythms, as insulin secretion rhythms persist when food is equally distributed over the day. ${ }^{67-70} \mathrm{In}$ addition, rats given six discrete meals throughout the day (calories consumed were not different between meals) showed the greatest insulin secretion 2 hours into the active period. ${ }^{19,68}$ Whole-body insulin sensitivity also exhibits a time-of-day dependence, peaking in the middle of the active period. Interestingly, both insulin and glucose levels acutely increase in the circulation immediately prior to waking, independent of feeding, an event termed the "Dawn Phenomenon". 71,72 This surge in blood glucose in the period prior to waking is likely secondary to relative hepatic insulin resistance, thus preparing the animal for the transition to activity (and increased glucose utilization). Collectively, insulin secretion and sensitivity appear to be temporally organized, likely in anticipation of increased activity upon waking, as well as increased food intake during the active period.

\section{Cortisol}

Cortisol is a catabolic glucocorticoid hormone secreted by the adrenal glands in the hypothalamic-pituitary-adrenal axis; hypothalamic release of corticotropin-releasing hormone stimulates pituitary release of adrenocorticotropic hormone, which in turn stimulates cortisol secretion. Cortisol modulates numerous metabolic processes, including stimulation of glycogenolysis, lipolysis, and proteolysis. Cortisol elicits a biphasic effect on glucose homeostasis, acutely inhibiting insulin secretion, and chronically inducing insulin resistance. ${ }^{73,74}$ In humans, circulating cortisol levels peak in the early morning $(\sim 1 \mathrm{am}),{ }^{75,76}$ promoting fuel mobilization at this time. ${ }^{77}$ The impact of corticosterone on metabolic homeostasis is time-of-day-dependent; hydrocortisone infused at $1 \mathrm{pm}$ (elevated at abnormal time) versus 5 am (elevated at normal time) results in augmented plasma glucose and insulin levels in humans. ${ }^{74}$ Collectively, diurnal rhythms in cortisol secretion and sensitivity likely serve to increase fuel availability at the beginning of the active period, in anticipation of increased energy expenditure upon waking.

\section{Growth hormone}

Growth hormone (GH) is an anabolic hormone produced/ secreted from the anterior pituitary gland. GH has pronounced effects on glucose, lipid, and protein metabolism. In essence, GH serves to promote protein synthesis, lipolysis (thereby shifting reliance toward fat oxidation), and gluconeogenesis, as well as eliciting insulin resistance. ${ }^{78}$ Circulating GH levels exhibit an ultradian pattern, which is species-, sex-, age-, and time-of-day-dependent. ${ }^{79-81} \mathrm{GH}$ secretion is triggered by GH- releasing hormone and is reduced by somatostatin; time-of-day-dependent rhythms in GH correspond more closely with $\mathrm{GH}$ - releasing hormone (relative to somatostatin). ${ }^{82,83}$ Increased GH levels during the rest/sleep period potentially function to increase circulating fatty acids, attenuating glucose (and amino acid) oxidation, thereby contributing toward increased glucose availability upon waking. ${ }^{84-86}$ Morning versus evening administration of GH (in GH-deficient subjects) showed differential effects, suggesting that only evening GH restored the metabolic profile of GH-proficient individuals ${ }^{87}$ Collectively, circadian rhythms in $\mathrm{GH}$ appear to maintain metabolic homeostasis during sleep and may contribute to the anticipatory increase in blood glucose prior to waking.

\section{Epinephrine/norepinephrine}

Epinephrine and norepinephrine are catecholamines synthesized from the amino acids tyrosine and phenylalanine. Epinephrine and norepinephrine are produced in the adrenal medulla and serve to mobilize energy by increasing glycogenolysis in liver and skeletal muscle, as well as lipolysis, following sympathetic nervous stimulation (ie, during 
the fight-or-flight response or exercise). Early findings in humans and animals have shown diurnal and circadian rhythms for both catecholamines in the circulation, with a trough during the relative rest phase. ${ }^{88,89}$ Scheer et $\mathrm{al}^{90}$ found that exercise performed in the morning resulted in an accentuated increase in catecholamine release in humans. Interestingly, a diurnal rhythm in adipose tissue sensitivity to epinephrine-stimulated lipolysis is highest at the end of the active period in rats. ${ }^{91}$ Norepinephrine also functions as an important neurotransmitter in the sympathetic nervous system and has central effects on feeding behavior; administration of hypothalamic norepinephrine suppresses feeding behavior in the dark phase and stimulates feeding behavior in the light phase of rats. ${ }^{92}$

\section{Intrinsic mediators}

Various metabolically relevant neurohumoral factors oscillate in a time-of-day-dependent manner. Many of these neurohumoral factors oscillate concomitantly with daily fluctuations in behaviors and are associated with predicted timing of distinct metabolic processes (eg, increased hepatic glycogen synthesis during the awake period, when insulin levels are elevated in ad libitum-fed animals). Such observations have led to models suggesting that rhythms in metabolic parameters are consequent to behavioral fluctuations, while neurohumoral factors serve as mediators. This "response" or "adaptation" model, therefore, relies on alterations in extrinsic factors to initiate perturbations in metabolism. However, this dogmatic model has been challenged in recent years, in light of observations that intrinsic mechanisms play a significant role. For example, multiple metabolic oscillations persist during constant conditions and/or dyssynchrony of organisms from a normal 24-hour environment. In the latter case, enforcing either 20 -hour or 28-hour sleep/wake and feeding/fasting cycles in human subjects reveals persistent 24-hour rhythms in circulating nutrients (eg, glucose, lipids) and neurohumoral factors (eg, norepinephrine) ${ }^{90,93}$ As such, an "intrinsic" or "anticipation" model has developed, wherein modulation of metabolic processes over the course of the day occurs independently of fluctuations in the environment. In reality, both models likely work in a coordinated fashion, facilitating metabolic homeostasis in the face of predicted fluctuations in energy supply/demand, yet ensuring sufficient flexibility in the event of abrupt changes in the environment. The "Circadian clocks" section reviews evidence that circadian clocks serve as an intrinsic mechanism modulating metabolic processes over the course of the day.

\section{Circadian clocks}

Circadian clocks are transcriptionally based cell autonomous mechanisms modulating biological processes in a temporally appropriate manner. ${ }^{1}$ This mechanism enables anticipation of environmental/extracellular/extrinsic stimuli and stresses prior to their onset. Circadian clocks have been identified in various organisms, ranging from distinct bacteria to both plants and animals. ${ }^{94}$ The mammalian circadian clock is composed of more than 15 transcriptional modulators, forming an interconnecting series of positive and negative feedback loops, with a free-running periodicity of approximately 24 hours. ${ }^{1,94}$ Central to the mechanism reside two bHLHPAS-containing transcription factors, CLOCK and BMAL1. Upon heterodimerization, CLOCK/BMAL1 binds to E-boxes within promoters of target genes, invariably resulting in induction..$^{95,96}$ These target genes include core clock components that generate negative feedback loops, such as multiple Period (PER1/2/3) and Cryptochrome (CRY1/2) isoforms, as well as REV-ERB $\alpha .{ }^{97-99}$ Once these proteins accumulate, PER/CRY heterodimers and REV-ERB $\alpha$ translocate back into the nucleus and negatively affect the CLOCK/BMAL1 heterodimer. More specifically, PER/CRY bind directly to CLOCK/BMAL1 (interfering with induction of target genes), while REV-ERB $\alpha$ binds to the promoter of the BMAL1 gene (repressing expression). ${ }^{97-99}$ Additional negative feedback loop components likely exist (eg, DEC1/2). ${ }^{100}$

Several aspects of the mammalian circadian clock warrant brief discussion. First, significant redundancy exists within the mechanism; overlapping functions of several core clock components include cryptochromes, periods, and CLOCK (redundancy with NPAS2). Indeed, mouse models of core clock component homozygous deletion reveal that only BMAL1 is essential for complete operation of the mammalian circadian clock (ie, clock function remains following genetic manipulation of other components, albeit with differences in the timing [ie, periodicity]). ${ }^{101}$ Second, although the clock mechanism is transcriptionally based, a number of posttranslational modifications are essential for normal operation (ie, correct phase and periodicity). For example, CK1 $\alpha$-mediated phosphorylation affects the stability of the Period isoforms, which is essential for delaying accumulation of this negative loop protein (relative to mRNA). ${ }^{102}$ Additional posttranslational modifications of clock components have been described, including acetylation, SUMoylation, ADPribosylation, and O-GlcNAcylation. ${ }^{37,103-107}$ Indeed, CLOCK possesses a histone acetyltransferase domain, which appears to be important for modulating acetylation and transcriptional activity of BMAL1. ${ }^{108}$ Third, circadian clocks have been 
described in essentially all mammalian cells, and can be classified depending upon tissue location. The central circadian clock is composed of a collection of approximately 10,000 specialized neurons within a region of the hypothalamus known as the suprachiasmatic nucleus (SCN). ${ }^{109}$ Peripheral circadian clocks are located in non-SCN cells (including other central nervous system regions). Although cell autonomous in nature, a hierarchy appears to exist, in a manner in which the SCN orchestrates the peripheral clocks. Entrainment of the SCN (primary example includes light entrainment via the retinohypothalamic tract), which results in neurohumoral fluctuations (via direct neural connections from the SCN, humoral factors released from the $\mathrm{SCN}$, and/or behaviorinduced changes in non-SCN-derived entrainment factors), is believed to modulate peripheral oscillator timing. ${ }^{1,109}$ However, it is noteworthy that SCN and peripheral clocks can be dissociated remarkably easily through various behaviors, including alteration of food intake patterns (as discussed in the following sections).

Clock components influence a multitude of target genes (beyond the clock mechanism itself), known as clock output or controlled genes, which in turn modulate cellular functions. It has been estimated that circadian clocks regulate as much as $13 \%$ of the transcriptome, in both a time-of-day- and tissue-dependent manner. ${ }^{110}$ Unbiased microarray and bioinformatics approaches suggest that clock-controlled genes can be assigned to a diverse set of biological/cellular functions, including transcription, translation, signal transduction, and metabolism. ${ }^{110-113}$ Clock control of transcriptional activators/ repressors allows amplification of a number of genes regulated by this mechanism (albeit indirectly). Translation (and protein degradation) is essential not only for the circadian clock to influence cellular functions (ie, daily turnover of proteins/enzymes within a functional cascade) but also for the normal operation of the clock mechanism itself. Clock control of signal transduction is likely critical for anticipation, allowing appropriate responsiveness to a stimulus/stress in a temporally appropriate manner. Circadian regulation of metabolic processes likely allows the cell to anticipate fluctuations in nutrient/energy supply and demand. Evidence in support of direct clock control of metabolism will now be discussed.

\section{Clock control of metabolism}

The hypothesis that circadian clocks regulate metabolic homeostasis, both directly (eg, expression of enzymes within a distinct metabolic pathway) and indirectly (eg, secretion of metabolically relevant neurohumoral factors) has received increasing interest over the past several decades. Here, we will focus primarily on cell and animal model (surgical and genetic)-based evidence suggesting a potential role for circadian clocks in metabolic homeostasis and discuss how they likely work in synchrony with extrinsic influences. In the latter case, significant attention will be given to insulin because of its established governing activity over intermediary metabolism. As before, only studies directly interrogating metabolic processes/parameters remain a major focus, while alterations in gene/protein expression will be considered possible mechanistic mediators (Figure 1). Although not discussed in detail here, it is important to note that circadian clock components (such as BMAL1 and CLOCK) may influence gene expression and metabolic processes independent of their circadian clock function.

\section{Whole body}

Disruption of circadian clock function influences metabolic homeostasis at multiple levels. At the whole-body level, both markers of acute (eg, nutrient clearance) and chronic (eg, body weight), metabolic perturbations have been interrogated. Initial SCN-ablation studies (a strategy that impairs not only central but also peripheral clock function) reported altered body weight in various rodent models. ${ }^{114-116}$ This intervention also results in profound alterations in glucose homeostasis, affecting both insulin-dependent and independent glucose disposal. ${ }^{16}$ Animal models of genetic manipulation of circadian clock components have also been investigated. Of these, germline CLOCK ${ }^{\Delta 19}$ mutant (loss of Exon 19 of the CLOCK gene, resulting in a dominant negative mutant) and BMAL1 null mice have been investigated to the largest extent (due to marked impact on circadian clock function); it is noteworthy that metabolic parameters have been investigated in other genetic models (eg, knockout [KO]/mutation of various PER and CRY isoforms), albeit to a lesser extent. In terms of body weight regulation, $\mathrm{CLOCK}^{\Delta 19}$ mutant mice present with increased adiposity (on the B6 background), while BMAL1 null mice are more susceptible to high-fatdiet-induced adiposity (at a young age). ${ }^{117,118}$ Both $\mathrm{CLOCK}^{\Delta 19}$ mutant and BMAL1 null mice exhibit decreased glucose tolerance, as indicated by an elevated amount of glucose in the circulation following an acute ( $<2$ hours) glucose load. ${ }^{119}$ Conversely, lipid tolerance is increased in $\mathrm{CLOCK}^{\Delta 19}$ mutant (ie, decreased triglyceride in circulation following an acute lipid load). ${ }^{120}$ Collectively, these data suggest that disruption of circadian clocks alters both long- (eg, adiposity) and shortterm (eg, glucose/lipid tolerance) metabolic homeostasis. In contrast, an extensive literature search was unable to identify 
information regarding the impact of circadian clock disruption on protein/amino acid tolerance.

Consistent with the first law of thermodynamics, alterations in adiposity/body weight suggest an imbalance between caloric intake and energy expenditure. This could arise through perturbations in food intake, digestion, and/or absorption following circadian clock disruption, as well as the balance between catabolic and anabolic pathways involved in nutrient/energy homeostasis. Evidence exists suggesting clock control of all these parameters. For example, CLOCK ${ }^{\Delta 19}$ mutant and BMAL1 null mice exhibit abnormalities in day-night patterns of food intake, such that a more even distribution of caloric intake is observed over the 24-hour day (as opposed to typical food intake predominance during the active/dark phase). ${ }^{11,121}$ Somewhat surprisingly, when both food intake and energy expenditure were investigated in BMAL1 null mice, no differences in total daily values of these parameters were found (although day-night differences were abolished). ${ }^{121}$ These data suggest that normal rhythms are important for metabolic homeostasis. Indeed, when sleep phase feeding is enforced in wild-type mice, increased adiposity is observed. ${ }^{122,123}$ Robust alterations in digestion/ absorption have been reported, particularly for $\mathrm{CLOCK}^{\Delta 19}$ mutant mice; these mice present with impaired lipid absorption, particularly on the Jcl:ICR background, likely due to clock control of MTP in intestinal epithelial cells. . $^{13,54,58,120}$ Collectively, these data lead to speculation that differences in digestion/absorption following circadian clock disruption contribute to increased weight gain, in the absence of daily total caloric intake and/or energy expenditure.

Glucose homeostasis following an acute glucose load illustrates the importance of balancing anabolic and catabolic processes, being orchestrated by fluctuations in insulin secretion and sensitivity. Amassing evidence suggests circadian clock control of insulin secretion. $\mathrm{CLOCK}^{\Delta 19}$ mutant mice exhibit decreased insulin levels during glucose tolerance tests compared to wild-type mice (when the glucose challenge is given either orally or intraperitoneally, thereby eliminating contributions of absorption). ${ }^{124}$ Similarly, islets isolated from these mice have blunted glucose-stimulated insulin secretion. ${ }^{124}$ Consistent with direct clock control, 24-hour oscillations in insulin gene expression persist in serum synchronized insulinoma cells. ${ }^{125}$ Furthermore, rhythms in insulin secretion persist during constant conditions, including continuous nutrition. ${ }^{68}$ Importantly, $\beta$-cell-specific BMAL1 null mice exhibit impaired insulin secretion..$^{70,124}$ Collectively, these data strongly support the concept that the circadian clock within the pancreatic $\beta$-cell directly modulates insulin secretion. In contrast to insulin secretion, the regulation of insulin sensitivity by cell autonomous clocks appears to be less conclusive. Insulin sensitivity oscillates over the course of the day, at both the whole-body and individual tissue level. With regards to control of these oscillations by circadian clocks, insulin tolerance tests suggested increased insulin sensitivity in CLOCK ${ }^{\Delta 19}$ mutant and BMAL1 null mice. ${ }^{19,126}$ However, utilization of hyperinsulinemic-euglycemic clamps (a more sensitive method for the assessment of whole-body insulin sensitivity) revealed decreased insulin-mediated glucose disposal in BMAL1 null mice (associated with decreased activation of insulin signaling components in the liver). ${ }^{118} \mathrm{As}$ outlined, investigation of clock control of insulin signaling in distinct tissues suggests cell type-specific regulation.

The aforementioned studies strongly support the concept that circadian clocks affect metabolic homeostasis at multiple levels. Important questions relate to the relative roles of celltype-specific circadian clocks, as well as how they integrate with extrinsic signals (eg, insulin) in an intact animal over the course of the day. Recent studies utilizing mouse models of tissue-specific circadian clock disruption have provided significant insight. Given known roles for liver, muscle, and adipose tissue, insights provided from models of genetic manipulation of circadian clocks within these tissues will be discussed next.

\section{Liver}

The liver plays a pivotal role in glucose, lipid, and protein/ nitrogen homeostasis. Anatomically, the liver serves as a first pass for dietary carbohydrate and amino acids, receiving these nutrients via the hepatic portal vein. Postprandial rise in both circulating nutrients and insulin suppresses hepatic glucose production, concomitant with stimulation of anabolic processes, such as glycogenesis and lipogenesis. Potential regulation of liver metabolism by circadian clocks has been implied through use of germline genetic manipulations (eg, CLOCK ${ }^{\Delta 19}$ mutant, BMAL1 null, and Cry1/2 double KO mice), resulting in perturbations of hepatic levels of lipogenesis, gluconeogenesis, and fatty acid $\beta$-oxidation, concomitant with alterations in insulin signaling components. ${ }^{119,127-130}$ To address a potential role for the hepatocyte circadian clock, both tissue-specific genetic manipulations in vivo and isolated cell culture systems have been employed. Lamia et al ${ }^{131}$ reported that hepatocyte-specific BMAL1 null mice exhibit increased glucose and insulin tolerance, as well as a propensity for fasting-induced hypoglycemia; this was associated with decreased expression of genes involved in gluconeogenesis (eg, glucose 6-phosphatase and 
glucose transporter 2). These observations are consistent with at least two scenarios, wherein the hepatocyte circadian clock: 1) directly regulates gluconeogenic enzymes and/or 2) indirectly modulates hepatic sensitivity to neurohumoral factors known to influence gluconeogenesis (eg, $\beta$-adrenergic and insulin stimulation). However, knockdown of BMAL1 in isolated hepatocytes decreases insulin-stimulated AKT activation (which would promote, not attenuate, gluconeogenesis). ${ }^{128}$ In contrast, the decrease in hepatic insulin sensitivity following liver-specific BMAL1 disruption is associated with decreased lipogenesis, as well as expression of enzymes known to regulate this metabolic process. ${ }^{128}$ It is noteworthy that Lipton et $\mathrm{al}^{46}$ have recently suggested a role for BMAL1 in protein synthesis regulation, potentially through direct interaction with the translation machinery. However, germline BMAL1 null mice were investigated, and as such, the relative role of the hepatocyte circadian clock in protein turnover in vivo remains to be established.

\section{Muscle}

Skeletal muscle is a metabolically diverse organ, capable of utilizing various substrates, depending on the conditions. Following ingestion of a carbohydrate-rich meal, skeletal muscle is responsible for approximately $60 \%$ of postprandial glucose disposal (ie, insulin-mediated). Insulin sensitivity and glucose utilization exhibit time-of-day-dependent oscillations in both intact skeletal muscle ex vivo as well as cultured myocytes in vitro. ${ }^{26,132}$ These data led Dyar et al ${ }^{133}$ to investigate the potential role of the skeletal myocyte circadian clock as a modulator of these processes. Through use of both constitutive and inducible skeletal myocyte-specific BMAL1 null mouse models, insulin-mediated skeletal muscle glucose uptake and oxidation were found to be dependent on the myocyte circadian clock. This was associated with clock control of GLUT4 (insulin-responsive glucose transporter), TBC1D1 (modulator of GLUT4 translocation), as well as PDP1 (a regulator of the pyruvate dehydrogenase complex). Somewhat surprisingly, no major differences in glucose or insulin tolerance were observed following ablation of BMAL1 in skeletal muscle, nor were differences in insulin-mediated AKT activation. ${ }^{133}$ Collectively, these findings suggest that the skeletal myocyte circadian clock directly regulates muscle glucose utilization but is not essential for maintenance of whole-body glucose homeostasis. However, it is important to note that time-of-day-dependent rhythms in insulin-mediated glucose utilization were not assessed, leaving the role of cell autonomous clocks on rhythms in skeletal muscle glucose utilization unanswered. Interestingly, cardiac muscle from cardiomyocyte-specific BMAL1 KO mice (CBK), as well as cardiomyocyte-specific $\mathrm{CLOCK}^{\Delta 19}$ mutant mice (CCM), also exhibits decreased glucose uptake and oxidation, associated with a loss of time-of-day-dependent rhythms in metabolism, suggesting that intramyocellular circadian clocks influence glucose utilization in all striated muscles over the course of the day ${ }^{37,112,134}$ In contrast, little is known regarding the role of the myocyte circadian clock on lipid, ketone body, and/or protein metabolism. Studies in CBK and CCM hearts reveal increased fatty acid oxidation, decreased triglyceride synthesis, decreased ketone body oxidation, decreased leucine oxidation, and increased protein synthesis, suggesting that the intramyocyte clock likely influences muscle metabolism at multiple levels. ${ }^{37,112,134,135}$

\section{Adipose tissue}

White and brown adipocytes have distinct roles in metabolic homeostasis. White adipocytes play an important role in the storage of excess nutrients in the form of triglyceride, as well as serving as an endocrine organ for a number of metabolically active adipokines (eg, leptin, adiponectin). Brown adipocytes are enriched with mitochondria, playing an important role in thermogenesis and energy expenditure. Given that both circulating nutrients and body temperature are circadian regulated, it is not surprising that emerging evidence suggests regulation of metabolic homeostasis by the circadian clock within the adipocyte. One of the first studies specifically investigating the contribution of the adipocyte circadian clock was in Drosophila, wherein targeted disruption of this mechanism through genetic means resulted in increased food intake during the inactive/sleep phase. ${ }^{136}$ More recently, Paschos et a $1{ }^{137}$ made similar observations in mice; adipocyte-specific BMAL1 null mice exhibit increased adiposity and inappropriate food intake during the inactive phase. The latter study suggested that altered fatty acid processing in adipocyte-specific BMAL1 null mice led to an imbalance in circulating polyunsaturated fatty acids, which in turn perturbed rhythmic feeding patterns. Despite increased adiposity, no differences in insulin sensitivity were identified between adipocyte-specific BMAL1 null mice and littermate controls. ${ }^{137}$ The precise impact of the adipocyte circadian clock on de novo fatty acid synthesis or triglyceride turnover remains unknown. In terms of brown adipocytes and thermogenesis, both germline and adipocytespecific BMAL1 null mice exhibit increased brown adipose tissue mass and are more cold tolerant, relative to wild-type controls. ${ }^{138,139}$ Studies by Gerhart-Hines et al ${ }^{140}$ suggest that REV-ERB $\alpha$ likely serves as a mediator of clock control of thermogenesis. 


\section{Physiologic roles and pathologic consequences}

Temporal partitioning is important for sequestering processes ranging from behaviors (such as feeding, activity, and sleep) to cellular processes (such as transcription, translation, and metabolism). In doing so, circadian regulation increases an organism's potential to be evolutionarily successful. ${ }^{141}$ A selective advantage exists for organisms that have the ability to anticipate time-of-day-dependent demands, thus being better prepared for the onset of predictable stressors. Examples include the availability or absence of food during feeding and fasting cycles, as well as physical activity associated with hunting, foraging, and avoiding predation. Rhythms in feeding and activity exist in both nocturnal and diurnal animals, and while anticipation to these behaviors is conferred by circadian clocks, both behaviors also fine-tune circadian rhythms in peripheral tissues. ${ }^{142,143}$ More specifically, the time at which food is consumed, or when exercise is performed, can entrain circadian clocks and therefore modulate rhythms in metabolism. Conversely, abnormalities in these behaviors will lead to circadian misalignment, associated with development of a host of cardiometabolic diseases. This section discusses the interrelationship between anticipation of, and entrainment to, behaviors such as food intake and exercise, in the context of circadian regulation of metabolism, as well as pathological consequences due to impairment of this relationship.

\section{Food intake}

\section{Rhythms in feeding}

It is essential to the survival of an organism to successfully acquire sufficient calories to match the energetic demands of life. Organisms have evolved various mechanisms to obtain, process, and store nutrients, many of which are under circadian control (illustrated in Figure 2). Under normal conditions, animals generally consume the majority of their calories during the active period (corresponding to the dark phase for nocturnal rodents)., ${ }^{4,17,144,145}$ In anticipation of feeding, animals will acutely increase spontaneous activity (known as food-anticipatory activity), likely to maximize food availability opportunities. ${ }^{146}$ Food-anticipatory activity is dampened during ad libitum feeding schedules, as seen in the majority of laboratory-based conditions, but is evident during time-restricted feeding schedules. ${ }^{147-149}$

Through the use of genetically modified mouse models, the roles of circadian clocks on feeding patterns have been investigated. For example, CLOCK ${ }^{\Delta 19}$ mutant mice display hyperphagia, associated with diminished time-of-daydependent rhythms in feeding, consuming equal amounts of food during the daytime and the night. ${ }^{117}$ Similarly, deletion of Per2 in mice (mPer2 $2^{--}$) abolished feeding rhythms, resulting in an increase in the amount of food consumed during the sleep (light) phase. Daytime hyperphagia in mPer2 ${ }^{-/-}$ mice was linked with $\alpha$-melanocyte-stimulating hormone (a neuroendocrine factor important in appetite regulation), which is normally increased during the sleep phase. Acute $\alpha$-melanocyte-stimulating hormone supplementation at the onset of sleep restored rhythmic food intake in mPer2 $2^{-1}$ mice. ${ }^{150}$ Liu et al ${ }^{151}$ have also highlighted a role for Per1 phosphorylation in diurnal feeding patterns; mutation of Per1 (at S714 residue) shortened the period of feeding, resulting in dyssynchrony between feeding and metabolic rhythms. As mentioned earlier, rhythms in food intake are also disrupted in adipocyte-specific BMAL1 null mice, resulting in increased food intake during the sleep phase. ${ }^{137}$ Collectively, these observations strongly support circadian clock influence over time-of-day-dependent rhythms in food intake.

\section{Feeding-induced clock entrainment}

Circadian clocks undoubtedly aid in the synchronization of anticipated food availability with metabolic processes. To maintain this selective advantage, clocks, therefore, must remain sufficiently responsive to fluctuations in the timing of food availability, to maintain synchronization. It is, therefore, not surprising that the timing of food intake has emerged as one of the strongest entrainment factors (zeitgeber) of peripheral circadian clocks. Evidence for such a concept was first described by Damiola et al, ${ }^{143}$ who reported phase shifts in clock component gene oscillations in the liver, kidney, and heart following restriction of food intake to the sleep phase. In contrast, the central ( $\mathrm{SCN}$ ) clock retained synchrony with the light/dark cycle (as opposed to feeding/fasting cycle). These initial studies also suggested that the rate of resynchronization of peripheral clocks in response to food intake was tissue specific, with the most rapid rate of resynchronization in the liver. ${ }^{143}$ Feeding-induced resynchronization has subsequently been reported in multiple studies. ${ }^{152,153}$ Collectively, these studies suggest that restricted feeding influences not only the phase but also the amplitude of clock gene oscillations in a tissue-specific manner. Such observations suggest differential responsiveness of organs to feeding-derived entrainment factors, relative to other signals (eg, direct innervation from the SCN). To date, the identity of a single feeding-derived entrainment factor is unknown, although multiple candidates 
have been proposed, including nutrient-derived signals (eg, O-GlcNAcylation). ${ }^{37}$

\section{Cardiometabolic consequence of disrupting the feeding-clock relationship}

Under physiologic conditions, synchrony is achieved between rhythms in feeding/fasting and metabolic processes, mediated in large part by circadian clocks. When dyssychrony occurs, through perturbations in the timing of food intake and/or circadian clock function, metabolic homeostasis is invariably disrupted, resulting in cardiometabolic diseases. Evidence for this concept stems from studies investigating metabolic perturbations during time-of-day-restricted feeding regimes and/ or following specific disruption of circadian clocks. Multiple indices of whole-body metabolism, including body temperature, oxygen consumption $\left(\mathrm{VO}_{2}\right)$, and respiratory exchange ratio (RER or respiratory quotient [RQ]), display robust circadian rhythms during ad libitum fed conditions, all of which are higher during the active period. Restricting food intake to the sleep phase revealed pronounced phase shifts of time-of-daydependent rhythms in these parameters, tending to increase during the light phase concomitant with food intake. ${ }^{154-158}$ In a study by Vollmers et al, ${ }^{159}$ light phase-restricted feeding shifted the peak, and increased the amplitude of the oscillation in RQ compared to ad libitum fed mice. Importantly, Bray et al ${ }^{152}$ revealed that not all parameters shifted to the same extent in response to light phase-restricted feeding, wherein substrate utilization (RQ) shifted by 10.3 hours (similar to food intake), rhythms in physical activity hardly shifted (only 0.5 hour), whereas rhythms in energy expenditure shifted by an intermediate level (6.6 hours). Thus, light phase-restricted feeding results in metabolic dyssynchrony at the whole-body level. Additional markers of dyssynchrony/metabolic perturbation following light phase-restricted feeding include phase shifts and/or loss of the rhythms of circulating glucose, insulin, cortisol, and triglycerides, as well as increased adiposity. These impairments in metabolic homeostasis are associated with differential clock gene shifts in distinct tissues, resulting in circadian dyssynchrony between organs. ${ }^{152}$ Interestingly, genetic manipulation of circadian clock gene components invariably results in impaired metabolic homeostasis and adiposity (as already detailed). Collectively, these observations suggest that light phase-restricted feeding impairs metabolic homeostasis, potentially through disruption of circadian clocks in a tissue-specific manner.

Unlike rodents, humans tend to eat discrete meals at distinct times of the day. In addition, few individuals consume all their calories during the inactive/sleep period. For these reasons, several studies have been designed to investigate whether consumption of calorically dense meals and/or of specific macronutrient content at certain time windows within the active period affects cardiometabolic parameters. In mice, consumption of a high-fat meal at the end of the active period was associated with increased adiposity, decreased glucose tolerance, hyperinsulinemia, and decreased cardiac function (relative to mice fed the same high-fat meal during the beginning of the active period). ${ }^{123,160}$ Interestingly, when placed on a high-fat diet in an ad libitum fashion, mice consume an abnormally high proportion of calories during the sleep phase, associated with phase and amplitude effects on peripheral circadian clock gene oscillations, as well as increased adiposity and depressed glucose and insulin tolerance. ${ }^{62}$ However, limiting consumption of a high diet only to the active period resulted in improvements in these cardiometabolic parameters (relative to ad libitum high-fat feeding), and increased the amplitude of circadian clock gene expression in multiple metabolically relevant peripheral tissues (eg, liver). ${ }^{52}$

\section{Exercise}

\section{Rhythms in exercise}

Spontaneous physical activity clearly exhibits a circadian rhythm. When presented with a running wheel, mice voluntarily run for a greater amount during the awake period; persistence of this rhythm in constant darkness reveals that these rhythms are driven by circadian clocks. Similarly, a number of studies have reported time-of-day-dependent rhythms in exercise performance. ${ }^{161-166}$ For example, sprint swim times, ${ }^{167}$ as well as running speed, power, and distance covered, ${ }^{165}$ are all faster in humans during afternoon trials. Interestingly, this corresponds to a time of day at which body temperature is increased. However, normalizing afternoon and morning body temperatures (ie, actively or passively cooling the body in the afternoon or heating in the morning) only partially accounts for performance. ${ }^{168,169}$ Rhythms in heat dissipation capacity (ie, vasodilation and sweating) during exercise may also modulate performance. ${ }^{170,171}$ Evidence suggests that the intrinsic properties within muscle, such as calcium handling and ATPase activity, contribute in a significant manner. ${ }^{172,173}$ Interestingly, recent findings suggest that individuals may achieve maximal exercise performance (assessed by cardiovascular endurance test) at different times of day, depending on their chronotype (ie, their individual tendency toward being a morning lark or night owl). ${ }^{174}$ Such observations suggest that intrinsic mechanisms (eg, circadian clocks) modulate exercise performance in a time-of-daydependent fashion. 


\section{Exercise-induced clock entrainment}

Exercise has emerged as a potent nonphotic zeitgeber in both animal models and humans. ${ }^{175-178}$ Mice exercised under constant darkness phase advance in response to exercise bouts during the subjective day, suggesting effects on the SCN clock. ${ }^{179}$ Furthermore, blinded mice also phase advance when given access to a running wheel. ${ }^{180}$ Exercise performed during the morning versus evening can differentially regulate core body temperature, melatonin, and parasympathetic tone in humans, in such a way that suggests exercise in the morning may benefit, whereas exercise in the evening may negatively impact, rhythms and sleep in humans. ${ }^{181}$ Indeed, nocturnal exercise of both high and low intensity significantly phase delays rhythms in melatonin and thyroid-stimulating hormone in humans. ${ }^{182}$ Exercise also influences the expression of clock genes in rodent peripheral tissues, consistent with entrainment. ${ }^{183,184}$ Furthermore, exercise directly increases clock gene expression in human and equine muscles. ${ }^{185,186}$ The temporal prescription of exercise can also be used to reduce entrainment time to a shift in light/dark cycle; reentrainment occurred more rapidly following intermittent access to a running wheel during the beginning of the new active period, ${ }^{176,187,188}$ but was slower when running wheel access was restricted to the light phase. ${ }^{187,188}$ Collectively, these data support the concept that exercise entrains both central and peripheral clocks, which in turn likely maintains synchrony between metabolic processes and anticipated periods of energetic demand.

\section{Consequence of disrupting the exercise-clock relationship}

It is somewhat difficult to dissociate the role of circadian clocks in exercise performance and adaptation, as numerous models of genetically disrupted clock function display underlying pathology. For example, cardiac and skeletal muscles in CLOCK ${ }^{\Delta 19}$ mutant, as well as Bmall and Rev-erb- $\alpha$ null, mice exhibit disorganized ultrastructure, defective contractile function, decreased mitochondrial volume, and impaired mitochondrial respiration. ${ }^{112,134,189-192}$ To dissociate potential adverse developmental effects, a recent study utilized an inducible Bmall $\mathrm{KO}$ restricted to skeletal muscle. Compared to constitutive skeletal muscle-specific Bmal1 ${ }^{-/}$mice, the inducible model did not display the same ultrastructural or contractile abnormalities. ${ }^{133}$ In fact, muscle-specific Bmal1 $1^{-/-}$mice displayed reduced in vivo contractile force, while inducible Bmal1 $1^{-/-}$mice were similar to controls. However, adaptation to exercise was not investigated. Interestingly, Pastore et a ${ }^{193}$ exercised CLOCK ${ }^{\Delta 19}$ mutant mice for 8 weeks and found that, despite having initially reduced exercise capacity (perhaps attributable to underlying deficits in cardiac and skeletal muscles), these mice were still able to adapt to exercise training (voluntary wheel running). Collectively, these findings suggest that a functional clock may be important in development and basal exercise performance, but may not be essential for adaptation. Additional studies are required to address this further, as well as related questions, such as whether the cardiometabolic benefits of exercise (eg, improved insulin sensitivity) are mediated in part by synchronizing circadian clocks, whether cell autonomous clocks influence time-of-day-dependent rhythms in exercise performance (perhaps through regulation of metabolic processes), and/or whether circadian clocks play a significant role in cardiovascular benefits of exercise (eg, physiologic cardiac hypertrophy).

\section{Summary}

Circadian rhythms in metabolism undoubtedly play critical roles in metabolic homeostasis. These rhythms appear to be the product of both anticipation of, and adaptation to, fluctuations in energy/nutrient supply/demand (secondary to changes in feeding and activity status). Accordingly, disruption of synchrony (through environmental and/or genetic means) invariably leads to impairment of metabolic homeostasis (evidenced by obesity, diabetes mellitus). Future studies are required to address multiple unanswered questions related to mediation of these rhythms (eg, relative roles of extrinsic versus intrinsic factors), their impact on exercise performance, and whether disruption contributes to cardiometabolic diseases in humans.

\section{Acknowledgments}

This work was supported by the National Heart, Lung, and Blood Institute (HL-074259 [MEY], HL-106199 [MEY], and HL-107709 [MEY]). GRM was supported by a training grant from the National Center for Medical Rehabilitation Research (1T32 HD-071866) and a Postdoctoral Fellowship from the American Heart Association (16POST27010009 [GRM]).

\section{Disclosure}

The authors report no conflicts of interest in this work.

\section{References}

1. Takahashi JS, Hong HK, Ko CH, McDearmon EL. The genetics of mammalian circadian order and disorder: implications for physiology and disease. Nat Rev Genet. 2008;9:764-775.

2. Balaban RS, Kantor HL, Katz LA, Briggs RW. Relation between work and phosphate metabolite in the in vivo paced mammalian heart. Science. 1986;232:1121-1123. 
3. Larue-Achagiotis C, Martin C, Verger P, Louis-Sylvestre J. Dietary self-selection vs. complete diet: body weight gain and meal pattern in rats. Physiol Behav. 1992;51:995-999.

4. Tempel DL, Shor-Posner G, Dwyer D, Leibowitz SF. Nocturnal patterns of macronutrient intake in freely feeding and food-deprived rats. $\mathrm{Am}$ J Physiol. 1989;256:R541-R548.

5. Leibowitz SF, Weiss GF, Walsh UA, Viswanath D. Medial hypothalamic serotonin: role in circadian patterns of feeding and macronutrient selection. Brain Res. 1989;503:132-140.

6. Redman RS, Sreebny LM. Changes in patterns of feeding activity, parotid secretory enzymes and plasma corticosterone in developing rats. J Nutr. 1976;106:1295-1306.

7. Girard-Globa A, Bourdel G, Lardeux B. Regulation of protein synthesis and enzyme accumulation in the rat pancreas by amount and timing of dietary protein. $J$ Nutr. 1980;110:1380-1390.

8. Bellavia SL, Sanz EG, Sereno R, Vermouth NT. Alpha-amylase circadian rhythm of young rat parotid gland: an endogenous rhythm with maternal coordination. Arch Oral Biol. 1992;37:429-433.

9. Fisher RB, Gardner ML. A diurnal rhythm in the absorption of glucose and water by isolated rat small intestine. J Physiol. 1976;254:821-825.

10. Fatima J, Iqbal CW, Houghton SG, et al. Hexose transporter expression and function in mouse small intestine: role of diurnal rhythm. $J$ Gastrointest Surg. 2009;13:634-641.

11. Balakrishnan A, Stearns AT, Rounds J, et al. Diurnal rhythmicity in glucose uptake is mediated by temporal periodicity in the expression of the sodium-glucose cotransporter (SGLT1). Surgery. 2008;143:813-818.

12. Houghton SG, Iqbal CW, Duenes JA, et al. Coordinated, diurnal hexose transporter expression in rat small bowel: implications for small bowel resection. Surgery. 2008;143:79-93.

13. Pan X, Hussain MM. Clock is important for food and circadian regulation of macronutrient absorption in mice. $J$ Lipid Res. 2009;50: 1800-1813.

14. Hussain MM, Pan X. Clock genes, intestinal transport and plasma lipid homeostasis. Trends Endocrinol Metab. 2009;20:177-185.

15. Iwashina I, Mochizuki K, Inamochi Y, Goda T. Clock genes regulate the feeding schedule-dependent diurnal rhythm changes in hexose transporter gene expressions through the binding of BMAL1 to the promoter/enhancer and transcribed regions. $J$ Nutr Biochem. 2011;22:334-343.

16. la Fleur SE, Kalsbeek A, Wortel J, Fekkes ML, Buijs RM. A daily rhythm in glucose tolerance: a role for the suprachiasmatic nucleus. Diabetes. 2001;50:1237-1243.

17. Whichelow MJ, Sturge RA, Keen H, et al. Diurnal variation in response to intravenous glucose. Br Med J. 1974;1:488-491.

18. Harfmann BD, Schroder EA, Esser KA. Circadian rhythms, the molecular clock, and skeletal muscle. J Biol Rhythms. 2015;30:84-94.

19. Kalsbeek A, la Fleur S, Fliers E. Circadian control of glucose metabolism. Mol Metab. 2014;3:372-383.

20. Kumar Jha P, Challet E, Kalsbeek A. Circadian rhythms in glucose and lipid metabolism in nocturnal and diurnal mammals. Mol Cell Endocrinol. 2015;418(Pt 1):74-88.

21. Conlee RK, Rennie MJ, Winder WW. Skeletal muscle glycogen content: diurnal variation and effects of fasting. Am JPhysiol. 1976;231:614-618.

22. Ishikawa K, Shimazu T. Circadian rhythm of liver glycogen metabolism in rats: effects of hypothalamic lesions. Am J Physiol. 1980;238:E21-E25.

23. Roesler WJ, Khandelwal RL. Diurnal variations in the activities of the glycogen metabolizing enzymes in mouse liver. Int $J$ Biochem. 1985; 17:81-85.

24. Zani F, Breasson L, Becattini B, et al. PER2 promotes glucose storage to liver glycogen during feeding and acute fasting by inducing Gys2 PTG and G L expression. Mol Metab. 2013;2:292-305.

25. Udoh US, Swain TM, Filiano AN, et al. Chronic ethanol consumption disrupts diurnal rhythms of hepatic glycogen metabolism in mice. $\mathrm{Am}$ J Physiol Gastrointest Liver Physiol. 2015;308:G964-G974.

26. Leighton B, Kowalchuk JM, Challiss RA, Newsholme EA. Circadian rhythm in sensitivity of glucose metabolism to insulin in rat soleus muscle. Am J Physiol. 1988;255:E41-E45.
27. Kida K, Nishio T, Yokozawa T, et al. The circadian change of gluconeogenesis in the liver in vivo in fed rats. J Biochem. 1980;88:1009-1013.

28. Barattini P, Larsen KR, Moore JG, Dayton MT. Circadian rhythm of pepsin efflux in the fasting rat stomach. Chronobiol Int. 1993;10:403-409.

29. Maouyo D, Sarfati P, Guan D, Morisset J, Adelson JW. Circadian rhythm of exocrine pancreatic secretion in rats: major and minor cycles. Am J Physiol. 1993;264:G792-G800.

30. Thaela MJ, Jensen MS, Cornelissen G, et al. Circadian and ultradian variation in pancreatic secretion of meal-fed pigs after weaning. $J$ Anim Sci. 1998;76:1131-1139.

31. Pan X, Terada T, Okuda M, Inui K. The diurnal rhythm of the intestinal transporters sglt 1 and pept 1 is regulated by the feeding conditions in rats. J Nutr. 2004;134:2211-2215.

32. Feigin RD, Klainer AS, Beisel WR. Factors affecting circadian periodicity of blood amino acids in man. Metabolism. 1968;17:764-775.

33. Wurtman RJ, Rose CM, Chou C, Larin FF. Daily rhythms in the concentrations of various amino acids in human plasma. $N$ Engl J Med. 1968;279:171-175.

34. Eriksson T, Voog L, Walinder J, Eriksson TE. Diurnal rhythm in absolute and relative concentrations of large neutral amino acids in human plasma. J Psychiatr Res. 1989;23:241-249.

35. Eriksson T, Wiesel K, Voog L, Hagman M. Diurnal rhythms in rat plasma amino acids. Life Sci. 1989;45:979-986.

36. Yao Z, DuBois DC, Almon RR, Jusko WJ. Modeling circadian rhythms of glucocorticoid receptor and glutamine synthetase expression in rat skeletal muscle. Pharm Res. 2006;23:670-679.

37. Durgan DJ, Pat BM, Laczy B, et al. O-GlcNAcylation, novel posttranslational modification linking myocardial metabolism and cardiomyocyte circadian clock. J Biol Chem. 2011;286:44606-44619.

38. Ruderman NB, Berger M. The formation of glutamine and alanine in skeletal muscle. J Biol Chem. 1974;249:5500-5506.

39. Ma D, Li S, Molusky MM, Lin JD. Circadian autophagy rhythm: a link between clock and metabolism? Trends Endocrinol Metab. 2012;23:319-325.

40. Ma D, Lin JD. Circadian regulation of autophagy rhythm through transcription factor C/EBP $\beta$. Autophagy. 2012;8:124-125.

41. Duffield GE, Best JD, Meurers BH, et al. Circadian programs of transcriptional activation, signaling, and protein turnover revealed by microarray analysis of mammalian cells. Curr Biol. 2002;12:551-557.

42. Pfeifer U, Scheller H. A morphometric study of cellular autophagy including diurnal variations in kidney tubules of normal rats. $J$ Cell Biol. 1975;64:608-621.

43. Pfeifer U, Strauss P. Autophagic vacuoles in heart muscle and liver. A comparative morphometric study including circadian variations in meal-fed rats. J Mol Cell Cardiol. 1981;13:37-49.

44. Ma D, Panda S, Lin JD. Temporal orchestration of circadian autophagy rhythm by C/EBP $\beta$. EMBO J. 2011;30:4642-4651.

45. Garlick PJ, Millward DJ, James WP. The diurnal response of muscle and liver protein synthesis in vivo in meal-fed rats. Biochem $J$. 1973;136:935-945.

46. Lipton JO, Yuan ED, Boyle LM, et al. The Circadian Protein BMAL1 Regulates Translation in Response to S6K1-Mediated Phosphorylation. Cell. 2015;161:1138-1151.

47. Rau E, Meyer DK. A diurnal rhythm of incorporation of L-[3H] leucine in myocardium of the rat. Recent Adv Stud Cardiac Struct Metab. 1975;7:105-110.

48. Duane WC, Gilberstadt ML, Wiegand DM. Diurnal rhythms of bile acid production in the rat. Am J Physiol. 1979;236:R175-R179.

49. Le Martelot G, Claudel T, Gatfield D, et al. REV-ERBalpha participates in circadian SREBP signaling and bile acid homeostasis. PLoS Biol. 2009;7:e1000181.

50. Noshiro M, Usui E, Kawamoto T, et al. Multiple mechanisms regulate circadian expression of the gene for cholesterol 7alpha-hydroxylase (Cyp7a), a key enzyme in hepatic bile acid biosynthesis. J Biol Rhythms. 2007;22:299-311.

51. Myant NB, Mitropoulos KA. Cholesterol 7 alpha-hydroxylase. J Lipid Res. 1977;18:135-153. 
52. Hatori M, Vollmers C, Zarrinpar A, et al. Time-restricted feeding without reducing caloric intake prevents metabolic diseases in mice fed a high-fat diet. Cell Metab. 2012;15:848-860.

53. Marrino P, Gavish D, Shafrir E, Eisenberg S. Diurnal variations of plasma lipids, tissue and plasma lipoprotein lipase, and VLDL secretion rates in the rat. A model for studies of VLDL metabolism. Biochim Biophys Acta. 1987;920:277-284.

54. Pan X, Zhang Y, Wang L, Hussain MM. Diurnal regulation of MTP and plasma triglyceride by CLOCK is mediated by SHP. Cell Metab. 2010;12:174-186.

55. Dallmann R, Viola AU, Tarokh L, Cajochen C, Brown SA. The human circadian metabolome. Proc Natl Acad Sci U SA. 2012;109:2625-2629.

56. Chua EC, Shui G, Lee IT, et al. Extensive diversity in circadian regulation of plasma lipids and evidence for different circadian metabolic phenotypes in humans. Proc Natl Acad Sci US A. 2013;110:14468-14473.

57. Escobar C, Diaz-Munoz M, Encinas F, Aguilar-Roblero R. Persistence of metabolic rhythmicity during fasting and its entrainment by restricted feeding schedules in rats. Am J Physiol. 1998;274:R1309-1316.

58. Pan X, Hussain MM. Diurnal regulation of microsomal triglyceride transfer protein and plasma lipid levels. J Biol Chem. 2007;282:24707-24719.

59. Shostak A, Meyer-Kovac J, Oster H. Circadian regulation of lipid mobilization in white adipose tissues. Diabetes. 2013;62:2195-2203

60. Stavinoha MA, Rayspellicy JW, Hart-Sailors ML, et al. Diurnal variations in the responsiveness of cardiac and skeletal muscle to fatty acids. Am J Physiol Endocrinol Metab. 2004;287:E878-E887.

61. Benavides A, Siches M, Llobera M. Circadian rhythms of lipoprotein lipase and hepatic lipase activities in intermediate metabolism of adult rat. Am J Physiol. 1998;275:R811-R817.

62. Kohsaka A, Laposky AD, Ramsey KM, et al. High-fat diet disrupts behavioral and molecular circadian rhythms in mice. Cell Metab. 2007;6:414-421.

63. Adamovich Y, Rousso-Noori L, Zwighaft Z, et al. Circadian clocks and feeding time regulate the oscillations and levels of hepatic triglycerides. Cell Metab. 2014;19:319-330.

64. Martin RJ, Stolz DJ, Buck DC. Diurnal changes in adipose and liver tissue metabolism of lean and obese Zucker rats. J Nutr. 1979;109:412-417

65. Suzuki M, Shimomura Y, Satoh Y. Diurnal changes in lipolytic activity of isolated fat cells and their increased responsiveness to epinephrine and theophylline with meal feeding in rats. J Nutr Sci Vitaminol. 1983;29:399-411.

66. Saltiel AR, Kahn CR. Insulin signalling and the regulation of glucose and lipid metabolism. Nature. 2001;414:799-806.

67. Goel N, Stunkard AJ, Rogers NL, et al. Circadian rhythm profiles in women with night eating syndrome. J Biol Rhythms. 2009;24:85-94.

68. Kalsbeek A, Strubbe JH. Circadian control of insulin secretion is independent of the temporal distribution of feeding. Physiol Behav 1998;63:553-558.

69. Shea SA, Hilton MF, Orlova C, Ayers RT, Mantzoros CS. Independent circadian and sleep/wake regulation of adipokines and glucose in humans. J Clin Endocrinol Metab. 2005;90:2537-2544.

70. Sadacca LA, Lamia KA, deLemos AS, Blum B, Weitz CJ. An intrinsic circadian clock of the pancreas is required for normal insulin release and glucose homeostasis in mice. Diabetologia. 2011;54:120-124.

71. Bolli GB, De Feo P, De Cosmo S, et al. Demonstration of a dawn phenomenon in normal human volunteers. Diabetes. 1984;33:1150-1153.

72. Bolli GB, Gerich JE. The "dawn phenomenon" - a common occurrence in both non-insulin-dependent and insulin-dependent diabetes mellitus. N Engl J Med. 1984;310:746-750.

73. Plat L, Byrne MM, Sturis J, et al. Effects of morning cortisol elevation on insulin secretion and glucose regulation in humans. Am J Physiol. 1996;270:E36-E42.

74. Plat L, Leproult R, L'Hermite-Baleriaux M, et al. Metabolic effects of short-term elevations of plasma cortisol are more pronounced in the evening than in the morning. $J$ Clin Endocrinol Metab. 1999;84:3082-3092.
75. Linkowski P, Van Onderbergen A, Kerkhofs M, et al. Twin study of the 24-h cortisol profile: evidence for genetic control of the human circadian clock. Am J Physiol. 1993;264:E173-E181.

76. Van Cauter E. Diurnal and ultradian rhythms in human endocrine function: a minireview. Horm Res. 1990;34:45-53.

77. Dickmeis T. Glucocorticoids and the circadian clock. J Endocrinol. 2009;200:3-22.

78. Moller N, Jorgensen JO. Effects of growth hormone on glucose, lipid, and protein metabolism in human subjects. Endocr Rev. 2009;30:152-177.

79. Avram AM, Jaffe CA, Symons KV, Barkan AL. Endogenous circulating ghrelin does not mediate growth hormone rhythmicity or response to fasting. J Clin Endocrinol Metab. 2005;90:2982-2987.

80. Pietrowsky R, Meyrer R, Kern W, Born J, Fehm HL. Effects of diurnal sleep on secretion of cortisol, luteinizing hormone, and growth hormone in man. J Clin Endocrinol Metab. 1994;78:683-687.

81. Gardi J, Obal F Jr, Fang J, Zhang J, Krueger JM. Diurnal variations and sleep deprivation-induced changes in rat hypothalamic GHRH and somatostatin contents. Am J Physiol. 1999;277:R1339-R1344.

82. Dimaraki EV, Jaffe CA, Bowers CY, Marbach P, Barkan AL. Pulsatile and nocturnal growth hormone secretions in men do not require periodic declines of somatostatin. Am J Physiol Endocrinol Metab. 2003;285:E163-E170.

83. Dimaraki EV, Jaffe CA, Demott-Friberg R, et al. Generation of growth hormone pulsatility in women: evidence against somatostatin withdrawal as pulse initiator. Am J Physiol Endocrinol Metab. 2001;280:E489-E495.

84. Boyle PJ, Avogaro A, Smith L, et al. Role of GH in regulating nocturnal rates of lipolysis and plasma mevalonate levels in normal and diabetic humans. Am J Physiol. 1992;263:E168-E172.

85. Rosenthal MJ, Woodside WF. Nocturnal regulation of free fatty acids in healthy young and elderly men. Metabolism. 1988;37:645-648.

86. Kousta E, Chrisoulidou A, Lawrence NJ, et al. The effects of growth hormone replacement therapy on overnight metabolic fuels in hypopituitary patients. Clin Endocrinol. 2000;52:17-24.

87. Jorgensen JO, Moller N, Lauritzen T, et al. Evening versus morning injections of growth hormone $(\mathrm{GH})$ in $\mathrm{GH}$-deficient patients: effects on 24-hour patterns of circulating hormones and metabolites. J Clin Endocrinol Metab. 1990;70:207-214.

88. Perlow M, Ebert MH, Gordon EK, et al. The circadian variation of catecholamine metabolism in the subhuman primate. Brain Res. 1978;139:101-113.

89. Linsell CR, Lightman SL, Mullen PE, Brown MJ, Causon RC. Circadian rhythms of epinephrine and norepinephrine in man. J Clin Endocrinol Metab. 1985;60:1210-1215.

90. Scheer FA, Hu K, Evoniuk H, et al. Impact of the human circadian system, exercise, and their interaction on cardiovascular function. Proc Natl Acad Sci U S A. 2010;107:20541-20546.

91. Suzuki M, Ide K, Saitoh S. Diurnal changes in glycogen stores in liver and skeletal muscle of rats in relation to the feed timing of sucrose. $J$ Nutr Sci Vitaminol. 1983;29:545-552.

92. Margules DL, Lewis MJ, Dragovich JA, Margules AS. Hypothalamic norepinephrine: circadian rhythms and the control of feeding behavior. Science. 1972;178:640-643.

93. Scheer FA, Hilton MF, Mantzoros CS, Shea SA. Adverse metabolic and cardiovascular consequences of circadian misalignment. Proc Natl Acad Sci U S A. 2009;106:4453-4458.

94. Edery I. Circadian rhythms in a nutshell. Physiol Genom. 2000;3:59-74.

95. Gekakis N, Staknis D, Nguyen H, et al. Role of the CLOCK protein in the mammalian circadian mechanism. Science. 1998;280:1564-1569.

96. Hogenesch J, Gu Y, Jain S, Bradfield C. The basic-helix-loop-helixpas orphan mop3 forms transcriptionally active complexes with circadian and hypoxia factors. Proc Natl Acad Sci U S A. 1998;95: 5474-5479.

97. Zylka M, Shearman L, Weaver D, Reppert S. Three period homologs in mammals: differential light responses in the suprachiasmatic circadian clock and oscillating transcripts outside of brain. Neuron. 1998;20:1103-1110. 
98. Miyamoto Y, Sancar A. Vitamin B2-based blue-light photoreceptors in the retinohypothalamic tract as the photoactive pigments for setting the circadian clock in mammals. Proc Natl Acad Sci US A. 1998;95:6097-6102.

99. Preitner N, Damiola F, Lopez-Molina L, et al. The orphan nuclear receptor REV-ERBalpha controls circadian transcription within the positive limb of the mammalian circadian oscillator. Cell. 2002;110:251-260.

100. Honma S, Kawamoto T, Takagi Y, et al. Dec1 and Dec2 are regulators of the mammalian molecular clock. Nature. 2002;419:841-844.

101. Bunger MK, Wilsbacher LD, Moran SM, et al. Mop3 is an essential component of the master circadian pacemaker in mammals. Cell. 2000;103:1009-1017.

102. Vielhaber E, Eide E, Rivers A, Gao ZH, Virshup DM. Nuclear entry of the circadian regulator mPER1 is controlled by mammalian casein kinase I epsilon. Mol Cell Biol. 2000;20:4888-4899.

103. Cardone L, Hirayama J, Giordano F, et al. Circadian clock control by SUMOylation of BMAL1. Science. 2005;309:1390-1394.

104. Hardin PE, Yu W. Circadian transcription: passing the HAT to CLOCK. Cell. 2006;125:424-426.

105. Kloss B, Price J, Saez L, et al. The Drosophila clock gene double-time encodes a protein closely related to human casein kinase Iepsilon. Cell. 1998;94:97-107.

106. Millar AJ. Clock proteins: turned over after hours? Curr Biol. 2000;10:R529-R531.

107. Asher G, Schibler U. Crosstalk between components of circadian and metabolic cycles in mammals. Cell Metab. 2011;13:125-137.

108. Doi M, Hirayama J, Sassone-Corsi P. Circadian regulator CLOCK is a histone acetyltransferase. Cell. 2006;125:497-508.

109. Cermakian N, Sassone-Corsi P. Multilevel regulation of the circadian clock. Nat Rev Mol Cell Biol. 2000;1:59-67.

110. Storch KF, Lipan O, Leykin I, et al. Extensive and divergent circadian gene expression in liver and heart. Nature. 2002;417:78-83.

111. Rudic RD, McNamara P, Reilly D, et al. Bioinformatic analysis of circadian gene oscillation in mouse aorta. Circulation. 2005;112:2716-2724.

112. Bray MS, Shaw CA, Moore MW, et al. Disruption of the circadian clock within the cardiomyocyte influences myocardial contractile function, metabolism, and gene expression. Am J Physiol Heart Circ Physiol. 2008;294:H1036-H1047.

113. Rey G, Cesbron F, Rougemont J, et al. Genome-wide and phase-specific DNA-binding rhythms of BMAL1 control circadian output functions in mouse liver. PLoS Biol. 2011;9:e1000595.

114. Marchant EG, Mistlberger RE. Anticipation and entrainment to feeding time in intact and SCN-ablated C57BL/6j mice. Brain Res. 1997;765:273-282.

115. Zucker I, Boshes M, Dark J. Suprachiasmatic nuclei influence circannual and circadian rhythms of ground squirrels. Am J Physiol. 1983;244:R472-R480.

116. Bartness TJ, Goldman BD, Bittman EL. Scn lesions block responses to systemic melatonin infusions in siberian hamsters. Am J Physiol. 1991;260:R102-R112.

117. Turek FW, Joshu C, Kohsaka A, et al. Obesity and metabolic syndrome in circadian clock mutant mice. Science. 2005;308:1043-1045.

118. Shi SQ, Ansari TS, McGuinness OP, Wasserman DH, Johnson CH. Circadian disruption leads to insulin resistance and obesity. Curr Biol. 2013;23:372-381.

119. Rudic RD, McNamara P, Curtis AM, et al. BMAL1 and CLOCK, two essential components of the circadian clock, are involved in glucose homeostasis. PLoS Biol. 2004;2:e377.

120. Oishi K, Atsumi G, Sugiyama S, et al. Disrupted fat absorption attenuates obesity induced by a high-fat diet in clock mutant mice. FEBS Lett. 2006;580:127-130.

121. Guo B, Chatterjee S, Li L, et al. The clock gene, brain and muscle Arnt-like 1, regulates adipogenesis via Wnt signaling pathway. FASEB J. 2012;26:3453-3463.
122. Arble DM, Bass J, Laposky AD, Vitaterna MH, Turek FW. Circadian timing of food intake contributes to weight gain. Obesity. 2009; 17:2100-2102.

123. Bray MS, Tsai JY, Villegas-Montoya C, et al. Time-of-day-dependent dietary fat consumption influences multiple cardiometabolic syndrome parameters in mice. Int J Obes. 2010;34:1589-1598.

124. Marcheva B, Ramsey KM, Buhr ED, et al. Disruption of the clock components CLOCK and BMAL1 leads to hypoinsulinaemia and diabetes. Nature. 2010;466:627-631.

125. Allaman-Pillet N, Roduit R, Oberson A, et al. Circadian regulation of islet genes involved in insulin production and secretion. Mol Cell Endocrinol. 2004;226:59-66.

126. Kennaway DJ, Owens JA, Voultsios A, Boden MJ, Varcoe TJ. Metabolic homeostasis in mice with disrupted Clock gene expression in peripheral tissues. Am J Physiol Regul Integr Comp Physiol. 2007;293:R1528-1537.

127. Doi R, Oishi K, Ishida N. CLOCK regulates circadian rhythms of hepatic glycogen synthesis through transcriptional activation of Gys2. J Biol Chem. 2010;285:22114-22121.

128. Zhang D, Tong X, Arthurs B, et al. Liver clock protein BMAL1 promotes de novo lipogenesis through insulin-mTORC2-AKT signaling. J Biol Chem. 2014;289:25925-25935.

129. Zhang EE, Liu Y, Dentin R, et al. Cryptochrome mediates circadian regulation of camp signaling and hepatic gluconeogenesis. Nat Med. 2010;16:1152-1156.

130. Peek CB, Affinati AH, Ramsey KM, et al. Circadian clock NAD+ cycle drives mitochondrial oxidative metabolism in mice. Science. 2013;342.

131. Lamia KA, Storch KF, Weitz CJ. Physiological significance of a peripheral tissue circadian clock. Proc Natl Acad Sci U S A. 2008;105:15172-15177.

132. Feneberg R, Lemmer B. Circadian rhythm of glucose uptake in cultures of skeletal muscle cells and adipocytes in Wistar-Kyoto, Wistar, Goto-Kakizaki, and spontaneously hypertensive rats. Chronobiol Int. 2004;21:521-538.

133. Dyar KA, Ciciliot S, Wright LE, et al. Muscle insulin sensitivity and glucose metabolism are controlled by the intrinsic muscle clock. Mol Metab. 2014;3:29-41.

134. Young ME, Brewer RA, Peliciari-Garcia RA, et al. Cardiomyocytespecific BMAL1 plays critical roles in metabolism, signaling, and maintenance of contractile function of the heart. J Biol Rhythms. 2014;29:257-276.

135. Tsai JY, Kienesberger PC, Pulinilkunnil T, et al. Direct regulation of myocardial triglyceride metabolism by the cardiomyocyte circadian clock. J Biol Chem. 2010;285:2918-2929.

136. Xu K, Zheng X, Sehgal A. Regulation of feeding and metabolism by neuronal and peripheral clocks in Drosophila. Cell Metab. 2008;8:289-300.

137. Paschos GK, Ibrahim S, Song WL, et al. Obesity in mice with adipocyte-specific deletion of clock component Arntl. Nat Med. 2012;18:1768-1777.

138. Li S, Yu Q, Wang GX, Lin JD. The biological clock is regulated by adrenergic signaling in brown fat but is dispensable for cold-induced thermogenesis. PLoS One. 2013;8:e70109.

139. Nam D, Guo B, Chatterjee S, et al. The adipocyte clock controls brown adipogenesis through the TGF- $\beta$ and BMP signaling pathways. $J$ Cell Sci. 2015;128:1835-1847.

140. Gerhart-Hines Z, Feng D, Emmett MJ, et al. The nuclear receptor REV-ERBalpha controls circadian thermogenic plasticity. Nature. 2013;503:410-413.

141. Antle MC, Silver R. Circadian insights into motivated behavior. Curr Top Behav Neurosci. Epub 2015 Sep 30.

142. Stokkan KA, Yamazaki S, Tei H, Sakaki Y, Menaker M. Entrainment of the circadian clock in the liver by feeding. Science. 2001;291:490-493.

143. Damiola F, Le Minh N, Preitner N, et al. Restricted feeding uncouples circadian oscillators in peripheral tissues from the central pacemaker in the suprachiasmatic nucleus. Genes Dev. 2000;14:2950-2961. 
144. Tsai JY, Villegas-Montoya C, Boland BB, et al. Influence of dark phase restricted high fat feeding on myocardial adaptation in mice. $J$ Mol Cell Cardiol. 2013;55:147-155.

145. Coomans CP, van den Berg SA, Lucassen EA, et al. The suprachiasmatic nucleus controls circadian energy metabolism and hepatic insulin sensitivity. Diabetes. 2013;62:1102-1108.

146. Stephan FK. The "other" circadian system: food as a Zeitgeber. J Biol Rhythms. 2002;17:284-292.

147. Storch KF, Weitz CJ. Daily rhythms of food-anticipatory behavioral activity do not require the known circadian clock. Proc Natl Acad Sci US A. 2009;106:6808-6813.

148. Mistlberger RE. Effects of scheduled food and water access on circadian rhythms of hamsters in constant light, dark, and light:dark Physiol Behav. 1993;53:509-516.

149. Mistlberger RE, Antle MC. Entrainment of circadian clocks in mammals by arousal and food. Essays Biochem. 2011;49:119-136.

150. Yang $\mathrm{S}$, Liu $\mathrm{A}$, Weidenhammer $\mathrm{A}$, et al. The role of $\mathrm{mPer} 2$ clock gene in glucocorticoid and feeding rhythms. Endocrinology. 2009; 150:2153-2160.

151. Liu Z, Huang M, Wu X, et al. PER1 phosphorylation specifies feeding rhythm in mice. Cell Rep. 2014;7:1509-1520.

152. Bray MS, Ratcliffe WF, Grenett MH, et al. Quantitative analysis of light-phase restricted feeding reveals metabolic dyssynchrony in mice. Int J Obes. 2013;37:843-852.

153. Reznick J, Preston E, Wilks DL, et al. Altered feeding differentially regulates circadian rhythms and energy metabolism in liver and muscle of rats. Biochim Biophys Acta. 2013;1832:228-238.

154. Challet E, Pevet P, Vivien-Roels B, Malan A. Phase-advanced daily rhythms of melatonin, body temperature, and locomotor activity in food-restricted rats fed during daytime. J Biol Rhythms. 1997;12:65-79.

155. Krieger DT, Hauser H, Krey LC. Suprachiasmatic nuclear lesions do not abolish food-shifted circadian adrenal and temperature rhythmicity. Science. 1977;197:398-399.

156. Satoh Y, Kawai H, Kudo N, Kawashima Y, Mitsumoto A. Timerestricted feeding entrains daily rhythms of energy metabolism in mice. Am J Physiol Regul Integr Comp Physiol. 2006;290:R1276-1283.

157. Tahara Y, Shibata S. Chronobiology and nutrition. Neuroscience. 2013;253:78-88.

158. Shamsi NA, Salkeld MD, Rattanatray L, et al. Metabolic consequences of timed feeding in mice. Physiol Behav. 2014;128:188-201.

159. Vollmers C, Gill S, DiTacchio L, et al. Time of feeding and the intrinsic circadian clock drive rhythms in hepatic gene expression. Proc Natl Acad Sci U S A. 2009;106:21453-21458.

160. Peliciari-Garcia RA, Goel M, Aristorenas JA, et al. Altered myocardial metabolic adaptation to increased fatty acid availability in cardiomyocyte-specific clock mutant mice. Biochim Biophys Acta. Epub December 22, 2015.

161. Drust B, Waterhouse J, Atkinson G, Edwards B, Reilly T. Circadian rhythms in sports performance - an update. Chronobiol Int 2005;22:21-44.

162. Atkinson G, Todd C, Reilly T, Waterhouse J. Diurnal variation in cycling performance: influence of warm-up. J Sports Sci. 2005;23:321-329.

163. Conroy RT, O'Brien M. Proceedings: diurnal variation in athletic performance. J Physiol. 1974;236:51P.

164. Baxter C, Reilly T. Influence of time of day on all-out swimming. $\mathrm{Br}$ J Sports Med. 1983;17:122-127.

165. Pullinger SA, Brocklehurst EL, Iveson RP, et al. Is there a diurnal variation in repeated sprint ability on a non-motorised treadmill? Chronobiol Int. 2014;31:421-432.

166. Souissi N, Bessot N, Chamari K, et al. Effect of time of day on aerobic contribution to the 30-s Wingate test performance. Chronobiol Int. 2007;24:739-748.

167. Kline CE, Durstine JL, Davis JM, et al. Circadian variation in swim performance. J Appl Physiol. 2007;102:641-649.

168. Robinson WR, Pullinger SA, Kerry JW, et al. Does lowering evening rectal temperature to morning levels offset the diurnal variation in muscle force production? Chronobiol Int. 2013;30:998-1010.
169. Edwards BJ, Pullinger SA, Kerry JW, et al. Does raising morning rectal temperature to evening levels offset the diurnal variation in muscle force production? Chronobiol Int. 2013;30:486-501.

170. Waterhouse J, Aizawa S, Nevill A, et al. Rectal temperature, distal sweat rate, and forearm blood flow following mild exercise at two phases of the circadian cycle. Chronobiol Int. 2007;24:63-85.

171. Aoki K, Shiojiri T, Shibasaki M, et al. The effect of diurnal variation on the regional differences in sweating and skin blood flow during exercise. Eur J Appl Physiol Occup Physiol. 1995;71:276-280.

172. Martin A, Carpentier A, Guissard N, van Hoecke J, Duchateau J. Effect of time of day on force variation in a human muscle. Muscle Nerve. 1999;22:1380-1387.

173. Guette M, Gondin J, Martin A. Time-of-day effect on the torque and neuromuscular properties of dominant and non-dominant quadriceps femoris. Chronobiol Int. 2005;22:541-558.

174. Facer-Childs E, Brandstaetter R. The impact of circadian phenotype and time since awakening on diurnal performance in athletes. Curr Biol. 2015;25:518-522.

175. Yamanaka Y, Hashimoto S, Tanahashi Y, et al. Physical exercise accelerates reentrainment of human sleep-wake cycle but not of plasma melatonin rhythm to 8-h phase-advanced sleep schedule. Am J Physiol Regul Integr Comp Physiol. 2010;298:R681-R691.

176. Yamanaka Y, Honma S, Honma K. Scheduled exposures to a novel environment with a running-wheel differentially accelerate re-entrainment of mice peripheral clocks to new light-dark cycles. Genes Cells. 2008; 13:497-507.

177. Yamanaka Y, Honma S, Honma K. Daily exposure to a running wheel entrains circadian rhythms in mice in parallel with development of an increase in spontaneous movement prior to running-wheel access. $\mathrm{Am}$ J Physiol Regul Integr Comp Physiol. 2013;305:R1367-R1375.

178. Edgar DM, Dement WC. Regularly scheduled voluntary exercise synchronizes the mouse circadian clock. Am J Physiol. 1991;261:R928-R933.

179. Reebs SG, Mrosovsky N. Large phase-shifts of circadian rhythms caused by induced running in a re-entrainment paradigm: the role of pulse duration and light. J Comp Physiol. 1989;165:819-825.

180. Yamada N, Shimoda K, Ohi K, Takahashi S, Takahashi K. Free-access to a running wheel shortens the period of free-running rhythm in blinded rats. Physiol Behav. 1988;42:87-91.

181. Yamanaka Y, Hashimoto S, Takasu NN, et al. Morning and evening physical exercise differentially regulate the autonomic nervous system during nocturnal sleep in humans. Am J Physiol Regul Integr Comp Physiol. 2015;309:R1112-R1121.

182. Buxton OM, Frank SA, L'Hermite-Baleriaux M, et al. Roles of intensity and duration of nocturnal exercise in causing phase delays of human circadian rhythms. Am J Physiol. 1997;273:E536-E542.

183. Pendergast JS, Branecky KL, Huang R, Niswender KD, Yamazaki S. Wheel-running activity modulates circadian organization and the daily rhythm of eating behavior. Front psychol. 2014;5:177.

184. Wolff G, Esser KA. Scheduled exercise phase shifts the circadian clock in skeletal muscle. Med Sci Sports Exerc. 2012;44:1663-1670.

185. Zambon AC, McDearmon EL, Salomonis N, et al. Time- and exercisedependent gene regulation in human skeletal muscle. Genome Biol. 2003;4:R61.

186. Murphy BA, Wagner AL, McGlynn OF, et al. Exercise influences circadian gene expression in equine skeletal muscle. Vet J. 2014;201: 39-45.

187. Castillo C, Molyneux P, Carlson R, Harrington ME. Restricted wheel access following a light cycle inversion slows re-entrainment without internal desynchrony as measured in Per2Luc mice. Neuroscience. 2011;182:169-176.

188. Dallmann R, Mrosovsky N. Scheduled wheel access during daytime: A method for studying conflicting zeitgebers. Physiol Behav. 2006;88:459-465.

189. Andrews JL, Zhang X, McCarthy JJ, et al. CLOCK and BMAL1 regulate $\mathrm{MyoD}$ and are necessary for maintenance of skeletal muscle phenotype and function. Proc Natl Acad Sci U SA. 2010;107:19090-19095. 
190. Kohsaka A, Das P, Hashimoto I, et al. The circadian clock maintains cardiac function by regulating mitochondrial metabolism in mice. PLoS One. 2014;9:e112811.

191. Lefta M, Campbell KS, Feng HZ, Jin JP, Esser KA. Development of dilated cardiomyopathy in BMAL1-deficient mice. Am J Physiol Heart Circ Physiol. 2012;303:H475-H485.
192. Woldt E, Sebti Y, Solt LA, et al. Rev-erb- $\alpha$ modulates skeletal muscle oxidative capacity by regulating mitochondrial biogenesis and autophagy. Nat Med. 2013;19:1039-1046.

193. Pastore S, Hood DA. Endurance training ameliorates the metabolic and performance characteristics of circadian clock mutant mice. $J$ Appl Physiol. 2013;114:1076-1084.

\section{Publish your work in this journal}

Nature and Science of Sleep is an international, peer-reviewed, open access journal covering all aspects of sleep science and sleep medicine, including the neurophysiology and functions of sleep, the genetics of sleep, sleep and society, biological rhythms, dreaming, sleep disorders and therapy, and strategies to optimize healthy sleep. The manuscript
Dovepress

management system is completely online and includes a very quick and fair peer-review system, which is all easy to use. Visit http://www. dovepress.com/testimonials.php to read real quotes from published authors. 